\title{
Aquaporin-1 Expression in Proliferative Vitreoretinopathy and in Epiretinal Membranes
}

\author{
Elie Motulsky, ${ }^{1,2,3}$ Dany Salik, ${ }^{1}$ Xavier Janssens, ${ }^{2,4}$ Bart Pion, ${ }^{2,4}$ Rebecca Dufrane, ${ }^{1}$ \\ Florence Chaput, ${ }^{1}$ Nargis Bolaky, ${ }^{1}$ Françoise Gregoire, ${ }^{1}$ Laure Caspers, ${ }^{2}$ Jason Perret, ${ }^{1}$ \\ François Willermain, ${ }^{2,3,5}$ and Christine Delporte ${ }^{1}$ \\ ${ }^{1}$ Laboratory of Pathophysiological and Nutritional Biochemistry, Université Libre de Bruxelles, Blg G/E, \\ CP 611, 808 Route de Lennik, 1070 Brussels, Belgium \\ ${ }^{2}$ Department of Ophthalmology, CHU Saint-Pierre, Université Libre de Bruxelles, Brussels, Belgium \\ ${ }^{3}$ Department of Ophthalmology, CHU Brugmann, Brussels, Belgium \\ ${ }^{4}$ Department of Ophthalmology, Saint-Anne Saint-Rémi Hospital, Brussels, Belgium \\ ${ }^{5}$ I.R.I.B.H.M., Université Libre de Bruxelles, Brussels, Belgium
}

Correspondence should be addressed to Elie Motulsky; elmotuls@ulb.ac.be

Received 29 October 2013; Accepted 9 December 2013; Published 4 February 2014

Academic Editors: K. Unlu and H. Xu

Copyright (C) 2014 Elie Motulsky et al. This is an open access article distributed under the Creative Commons Attribution License, which permits unrestricted use, distribution, and reproduction in any medium, provided the original work is properly cited.

Purpose. Aquaporin-1 (AQP1) is involved in cell migration and proliferation; therefore, the purpose of the study was to investigate its expression in proliferative vitreoretinopathy (PVR) and epiretinal membranes (ERM). Methods. 19 membranes from PVR and ERM were collected following eye surgery. AQP1 mRNA and protein expressions were determined by RT-qPCR and immunofluorescence in the membranes from PVR and ERM. Results. AQP1 mRNA and protein were expressed in both PVR and ERM as shown by RTqPCR and immunofluorescence. AQP1 protein expression was heterogeneous among and between PVR and ERM and colocalized with alpha-smooth muscle actin ( $\alpha$ SMA) and with glial fibrillary acidic protein (GFAP). There were a higher percentage of cells coexpressing AQP1 and $\alpha$ SMA than AQP1 and GFAP. GFAP and $\alpha$ SMA did not colocalize. Conclusion. Our data show for the first time AQP1 expression in both PVR and ERM. AQP1 is expressed mostly by the $\alpha$ SMA-positive cells, presumably myofibroblasts, but also by GFAP-positive cells, assumed to be glial cells. These original findings warrant further functional investigations aiming at studying the potential role of AQP1 in cell migration and proliferation occurring during the development of PVR and ERM.

\section{Introduction}

Proliferative vitreoretinopathy (PVR) and epiretinal membranes (ERM) are both characterized by abnormal migration and proliferation of retinal cells that form contractile membranes [1-6]. In ERM, this process is usually limited to the formation of membranes above the macula that can contract and wrinkle the retina causing patients to complain of visual impairment such as metamorphopsia, micro- or macropsia, blurred vision, and occasionally monocular diplopia [7-9]. Most ERM are idiopathic but can be associated with ocular diseases (e.g., diabetic retinopathy, retinal vein occlusion, postretinal, or cataract surgeries) [10]. In contrast, PVR follows retinal detachment (RD) and/or a traumatic condition $[11,12]$. Classically, PVR membranes can develop on both sides of the retina and progress deeper in the vitreous [13, 14]. Both PVR and ERM are made from different cell types including immune, glial, fibroblast-like and RPE cells [15-18].

Aquaporins (AQPs), a gene family of water transmembrane channel proteins, not only ensure transcellular water transport across biological membranes [19] but also have been recently described as implicated in cell migration and proliferation [20,21]. Several papers have shown that AQP1 is essential for cell migration of different cell types [20, 22-27]. Interestingly, AQP1 expression has been described on several retinal cell types during physiological and pathological conditions [28-33]. As a prerequisite to address the putative functional role of AQP1 in PVR and ERM development, it is first necessary to investigate the expression of AQP1 in PVR and ERM. 
TABLE 1: Clinical data related to PVR and ERM membranes.

\begin{tabular}{lccccc}
\hline Patient number & Age & Sex & Membrane type & Analysis & Previous use of silicone oil \\
\hline 1 & 44 & M & PVR II & IF & Yes \\
2 & 46 & M & PVR II & IF & Yes \\
3 & 19 & M & PVR II & IF & Yes \\
4 & 32 & M & ERM II & IF & Yos \\
5 & 64 & M & ERM II & IF & Yes \\
6 & 65 & M & PVR II & IF & No \\
7 & 68 & M & ERM I & IF & No \\
8 & 73 & F & ERM & IF & Yes \\
9 & 58 & F & PVR II & IF & No \\
10 & 74 & M & ERM I & RT-qPCR & No \\
11 & 63 & F & PVR II & NT-qPCR \\
14 & 51 & M & PVR II & RT-qPCR & No \\
12 & 26 & M & PVR I & No \\
13 & 80 & F & ERM I* & RT-qPCR & No \\
15 & 76 & ERM I* & RT-qPCR & No \\
16 & 78 & F & ERM I* & RT-qPCR & No \\
17 & 45 & F & ERM I* & RT-qPCR & RT-qPCR \\
18 & 65 & FRM I* & ERM I* & & \\
\hline
\end{tabular}

PVR I: no previous surgery; PVR II: patients with previous surgery; ERM I: idiopathic; ERM II: other conditions associated such as diabetic retinopathy or PVR or previous surgery; M: male; F: Female; IF: immunofluorescence; RT-qPCR: real-time quantitative polymerase chain reaction; ${ }^{\#}$ PVR pooled together to perform RT-qPCR; ${ }^{*}$ idiopathic ERM pooled together. Age is expressed in years.

\section{Material and Methods}

2.1. Membranes from PVR and ERM. PVR and ERM membranes were removed during surgical treatment of patients, in agreement with the appropriate ethical protocol approved by the institutional review boards of CHU Saint-Pierre and Sainte-Anne Saint-Rémi Hospital. The study was conducted according to the tenets of the Declaration of Helsinki. Conventional vitreoretinal surgery was performed by three different surgeons using a two- or three-port system. Size of vitreoretinal instruments was rarely 20 gauge and routinely 23 gauge. Membranes from 19 eyes from 19 patients ( 7 women and 12 men), with an average age of $59 \pm 4(n=19)$, were collected (Table 1).

2.2. RNA Extraction and cDNA Synthesis. Membranes from PVR and ERM were immediately immersed in RNA stabilization solution. Pools of three membranes from PVR (1 woman and 2 men; age: $49 \pm 11, n=3)$ and of six membranes from primary ERM ( 3 women and 3 men; age: $73 \pm 6$, $n=6$ ) were prepared for RNA extraction. RNA extraction, RNA concentration determination, and cDNA synthesis were carried out as previously described [34].

2.3. Primer Design and RT-qPCR. Primers were designed as previously described [34] to ensure optimal DNA polymerization efficiency and amplification specificity, as well as optimal amplicon length (100 bp to $180 \mathrm{bp}$ ). Primer pair efficiency and capability to amplify genomic DNA were determined as previously described [34]. The RT-qPCR reaction was performed as previously described using $2.5 \mathrm{ng}$ cDNA as template [34]. Amplification curves and final amplification melt curve were controlled using the StepOne Software version 2.1 (Applied Biosytems, Carlsbad, CA, USA) and were checked for proper exponential amplification and single $T_{m}$ peak in the final melt curve after the 40 cycles amplification profile. All nontarget negative controls were performed using Molecular Biology Grade Water-RNase/DNase-free water instead of cDNA.

2.4. Double Immunofluorescent Labelling on Membranes from PVR and ERM. PVR and ERM membranes were fixed in $4 \%$ buffered formaldehyde and paraffin-embedded and then $3 \mu \mathrm{m}$-thick sections were cut. PVR and ERM membranes sections were incubated with AQP1 specific primary antibodies (rabbit polyclonal affinity purified anti-AQP1, dultion $1: 500$ [35]), and alpha-smooth muscle actin $(\alpha \mathrm{SMA}=$ Acta2 $)$, dilution 1:500 (Invitrogen), or a rabbit (Sigma-Aldrich, Saint-Louis, MO, USA) or a mouse monoclonal to glial fibrillary acidic protein (GFAP), dilution 1:500 (Millipore, Billerica, MA, USA); overnight at $4^{\circ} \mathrm{C}$, followed by incubations with biotinylated anti-rabbit IgG, streptavidin-Cyanin2 (Jackson Immunoresearch, West Grove, PA), and anti-mouse IgG coupled with cyanin3 (Jackson Immunoresearch, West Grove, PA). Cyanin 2 and cyanin 3 are, respectively, green and red fluorochromes as previously described [35]. Cell nuclei were stained with Hoechst 33258 (1:5000; Sigma-Aldrich, Saint-Louis, MO, USA). Tissue sections were mounted using FluorSave reagent (Calbiochem, Gibbstown, NJ, USA). As negative controls, sections were incubated with the secondary antibody alone. Images were captured using an Axiocam 
TABLE 2: Gene symbols, gene name, accession number, primers sequences, amplicon sizes, and primer efficiencies of the tested genes (mean \pm S.E.M., $n=3)$.

\begin{tabular}{|c|c|c|c|c|c|}
\hline $\begin{array}{l}\text { Gene } \\
\text { symbols }\end{array}$ & Gene name & Accession number & Primer sequences & $\begin{array}{l}\text { Amplicon size } \\
\text { (bp) }\end{array}$ & $\begin{array}{c}\text { Primer } \\
\text { efficiency (\%) }\end{array}$ \\
\hline hsAQP1 & Aquaporin-1 & NM_198098 & $\begin{array}{l}\text { F: 5'-TGGACACCTCCTGGCTATTG-3' } \\
\text { R: 5'-GGGCCAGGATGAAGTCGTAG-3' }\end{array}$ & 164 & $107 \pm 3$ \\
\hline hsActa2 & Smooth muscle actin & NM_001141945.1 & $\begin{array}{l}\text { F: } 5^{\prime} \text {-GCTATGTGTGAAGAAGAGG-3' } \\
\text { R: } 5^{\prime} \text {-CACGTAGCTGTCTTTTTGT-3' }\end{array}$ & 171 & $97 \pm 1$ \\
\hline hsGFAP & $\begin{array}{l}\text { Glial fibrillary acidic } \\
\text { protein }\end{array}$ & NM_002055.4 & $\begin{array}{l}\text { F: } 5^{\prime} \text {-GTCAGAAGGCCACCTCAAGA-3' } \\
\text { R: } 5^{\prime} \text {-CCTGCCTCACATCACATCCT-3' }\end{array}$ & 109 & $96 \pm 2$ \\
\hline hsATP5B & ATP synthase subunit beta & NM_001686.3 & $\begin{array}{l}\text { F: } 5^{\prime} \text {-AGAGGTCCCATCAAAACCAAAC-3' } \\
\text { R: } 5^{\prime} \text {-AAAAGCCCAATTTTGCCACC- } 3^{\prime}\end{array}$ & 152 & $101 \pm 2$ \\
\hline hsHPRT1 & $\begin{array}{l}\text { Hypoxanthine } \\
\text { phosphoribosyltransferase } 1\end{array}$ & NM_000194.2 & $\begin{array}{l}\text { F: } 5^{\prime} \text {-TGGCGTCGTGATTAGTGATG-3' } \\
\text { R: } 5^{\prime} \text {-CTCGAGCAAGACGTTCAGTC-3' }\end{array}$ & 137 & $98 \pm 1$ \\
\hline
\end{tabular}

TABLE 3: RT-qPCR Cq values of the tested genes in both PVR and ERM pools. Quantification cycles (Cq) were determined in duplicate in both PVR and ERM pools of samples. Data are expressed as the mean \pm S.E.M. of the duplicate measures.

\begin{tabular}{|c|c|c|c|}
\hline \multirow{2}{*}{ Gene symbol } & \multicolumn{3}{|c|}{ Cq values } \\
\hline & PVR & ERM & + Ctrl cDNA \\
\hline hsAQP1 & $30.64 \pm 0.02$ & $28.66 \pm 0.25$ & $25.72 \pm 0.16$ \\
\hline hsActa2 & $27.06 \pm 0.53$ & $30.10 \pm 0.19$ & $23.91 \pm 0.11$ \\
\hline hsGFAP & $20.81 \pm 0.03$ & $25.83 \pm 0.07$ & $21.80 \pm 0.65$ \\
\hline hsATP5B & $24.64 \pm 0.07$ & $28.78 \pm 0.04$ & $21.04 \pm 0.13$ \\
\hline hsHPRT1 & $26.84 \pm 0.06$ & $31.29 \pm 0.04$ & $26.45 \pm 0.04$ \\
\hline
\end{tabular}

MRB fluorescent microscope (Zeiss, Göttingen, Germany) running AxioVision digital image processing software.

2.5. Labelling Quantification and Statistic Analysis. The number of total cells (DAPI-fluorescent cells) and the number of labelled cells were counted by two independent investigators in areas of $0.32 \mathrm{~mm} \times 0.45 \mathrm{~mm}(\times 20$ magnification $)$ and $0.65 \mathrm{~mm} \times 0.9 \mathrm{~mm}(\times 10$ magnification $)$ using both tissue sections labelled with AQP1 and GFAP or with AQP1 and $\alpha$ SMA. The data are expressed as percentage of total cell number (DAPI-labelled cells) (mean \pm S.E.M.). Spearman correlation coefficients were computed to assess the relation between the variables investigated. Paired Student's $t$-test was used to assess the significant difference between the number of cells labelled with $\alpha$ SMA and GFAP and the number of cells labelled with AQP1/GFAP and AQP1/ $\alpha$ SMA. A $P$ value $<0.05$ is considered as statistically significant. Data were analyzed using the Statistical Package for the Social Sciences (IBMSPSS Inc., Chicago, USA).

\section{Results}

3.1. $m R N A$ Expression of AQP1 in Membranes from PVR and $E R M$. Gene symbols, gene names, accession numbers, primers sequences, amplicon sizes, and primer efficiencies of the tested genes are described in Table 2; potential genomic DNA amplification using the primer pairs was also tested (data not shown). The genes tested included the genes of interest: AQP1, Acta2 (or $\alpha$ SMA), and GFAP, as well as two reference genes: ATP5B and HPRT1. All primers used to amplify these genes had efficiencies comprised between 96 and 107\% and did not amplify genomic DNA in the RT-qPCR reaction protocol used [34] (Table 2 and Figure 1, second column).

Both membranes from PVR and ERM pools displayed significant expression of AQP1, Acta2 ( $\alpha$ SMA), and GFAP mRNAs, as well as of ATP5B and HPRT1 mRNAs (Figure 1, second column). RT-qPCR amplification curves showed significant quantification cycle $(\mathrm{Cq})$ values for the tested genes in both membranes from PVR and ERM pools (Table 3).

$\mathrm{Cq}$ values obtained for the positive control are indicated in Table 3 and in Figure 1, first column. Positive control cDNA (+ Ctrl cDNA) used liver cDNA for AQP1 and HPRT1, brain cDNA for GFAP and ATP5B, and kidney cDNA for Acta2 ( $\alpha$ SMA). RT-qPCR amplification showed typical exponential behaviour for all the tested genes using positive control cDNA or using PVR and ERM membranes cDNA (Figure 1, first column). As expected, all nontarget negative controls did not yield signal amplification. Due to the low amount of cells in membranes from PVR and ERM, samples were pooled. Nevertheless, it was technically impossible to test the purified RNA for possible genomic DNA contamination. Nonetheless, the RNAs were safe for use in RT-qPCR as all primers used did not amplify purified genomic DNA tested in control RT-qPCR reactions (Figure 1, second column). Furthermore, careful analysis of the superimposed RT-qPCR melt curves obtained following 40 q-PCR cycles of the positive control cDNA, PVR cDNA, and ERM cDNA confirmed a single amplicon $T_{m}$ peak and the absence of a genomic DNA contribution. The amplified signals were consequently considered 

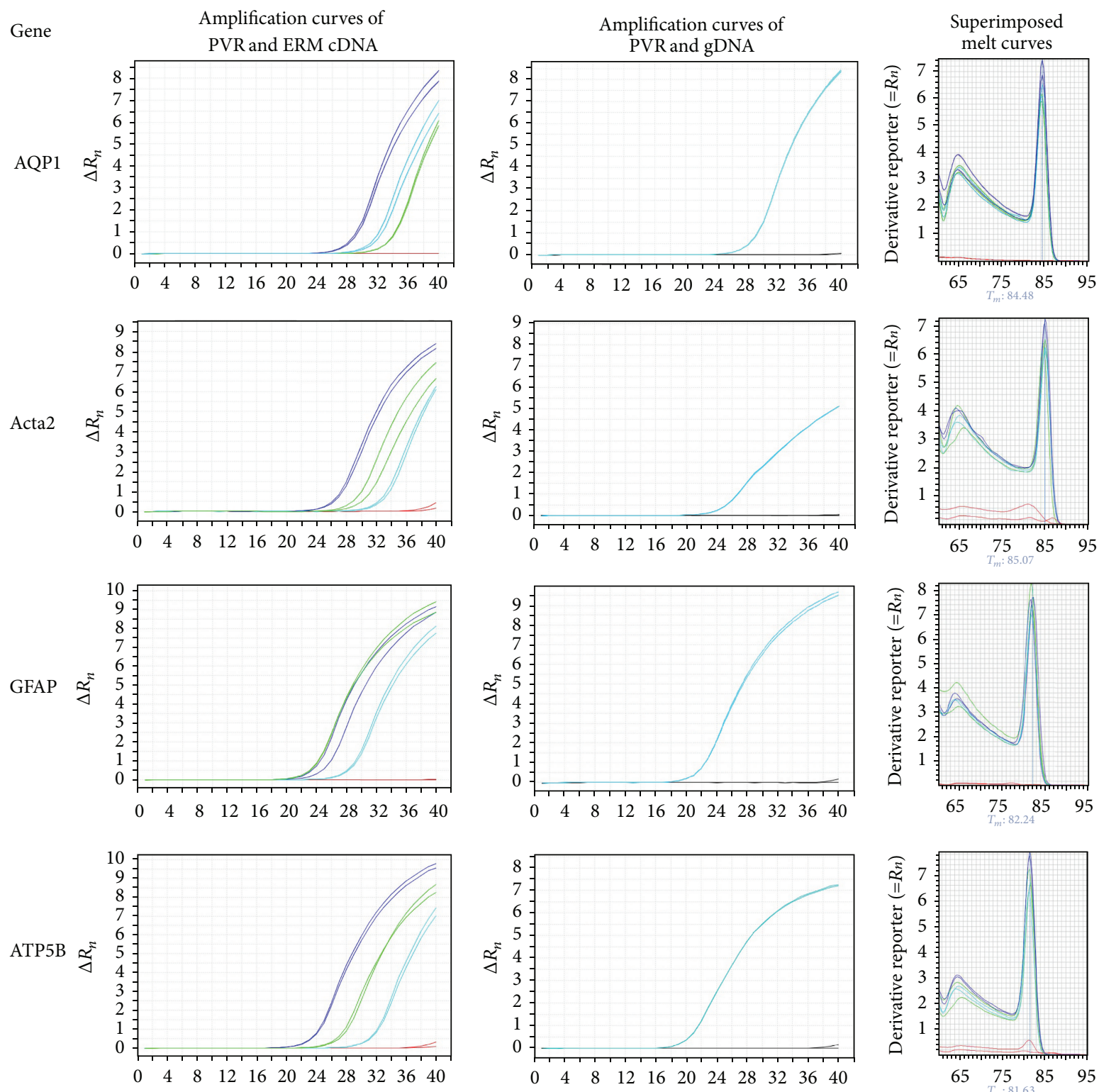

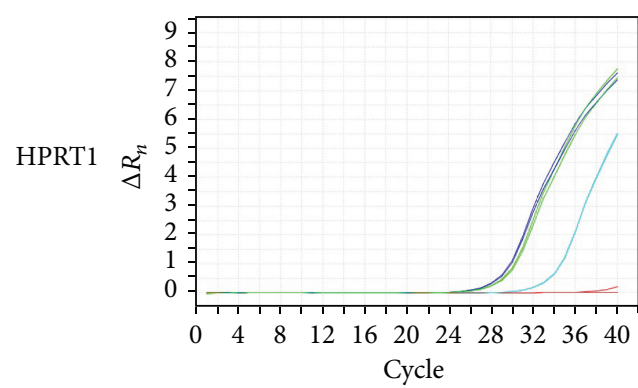

(a)

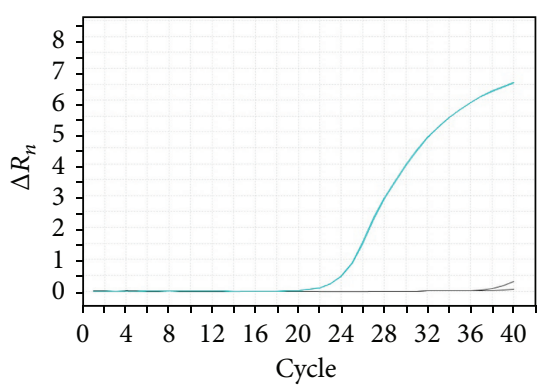

(b)

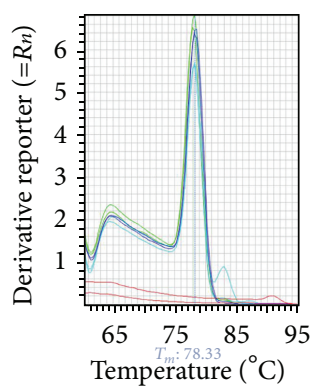

(c)

FIGURE 1: AQP1 mRNA expression in membranes from PVR and ERM. First Column: cDNAs from pools of 3 PVR membranes or 6 ERM membranes were used for RT-qPCR. The amplification curves obtained with cDNA from a positive control (mallow curve), a negative control (red curve), PVR (green curve), and ERM (light blue curve) are shown for each tested gene. Second Column: RT-qPCR amplification curves obtained with cDNA from a positive control (light blue curve) or $2.5 \mathrm{ng}$ genomic DNA (gDNA) (black curve) are shown for each tested gene primers. Third Column: RT-qPCR melt curves obtained following 40 RT-qPCR cycles and with cDNA from a positive control (mallow curve), PVR (green curve), and ERM (light blue curve) or genomic DNA (red curve) are shown for each tested gene. 


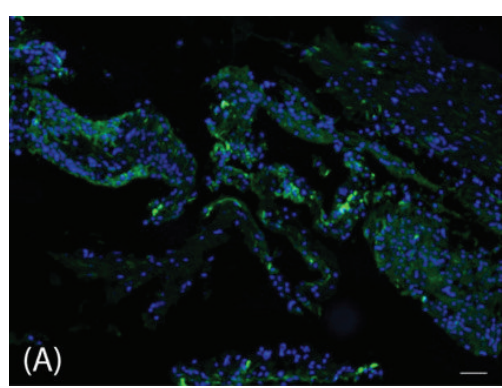

(a)

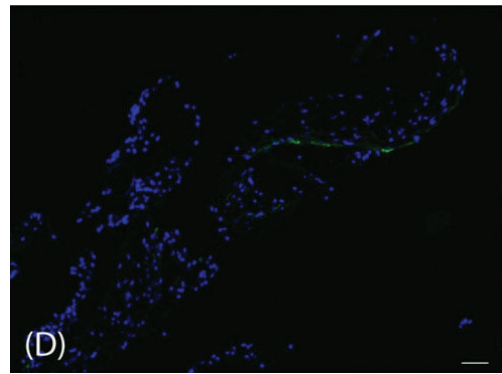

(d)

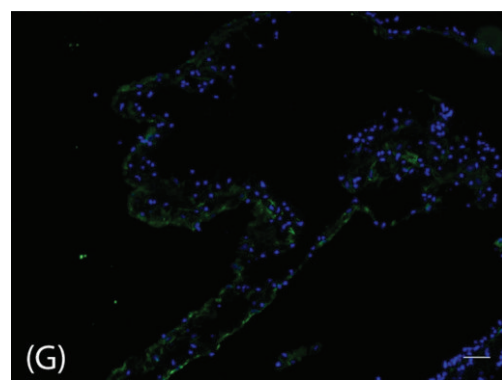

(g)

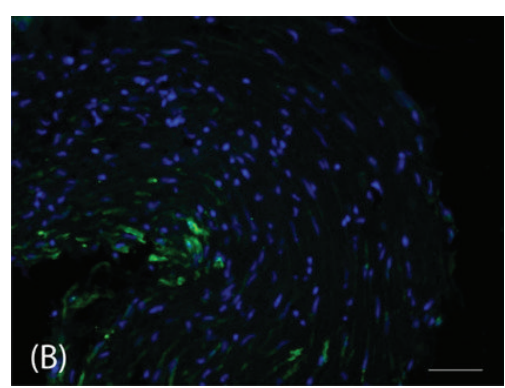

(b)

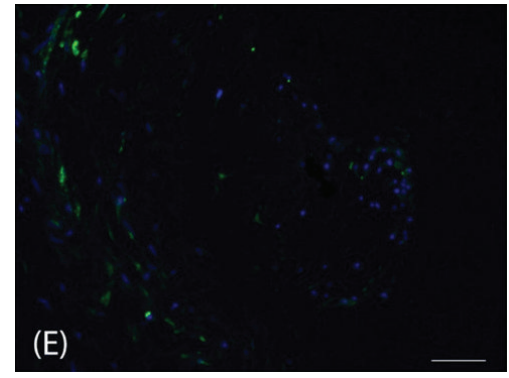

(e)

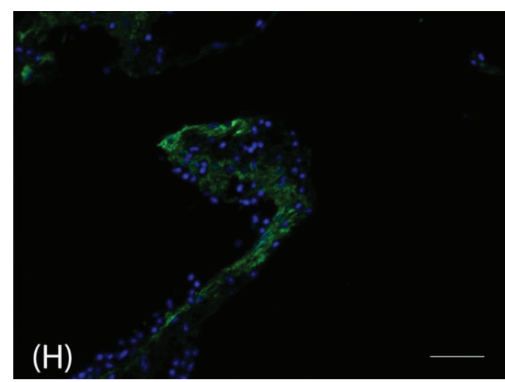

(h)

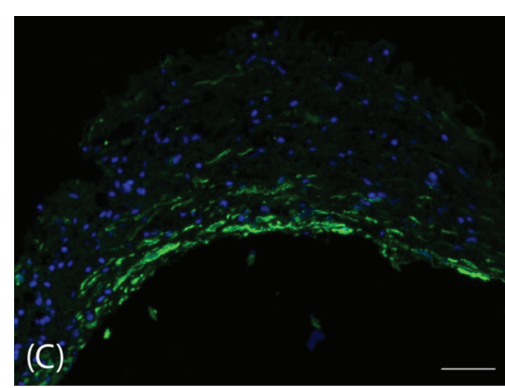

(c)

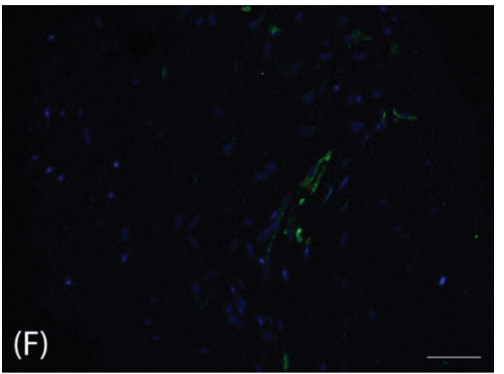

(f)

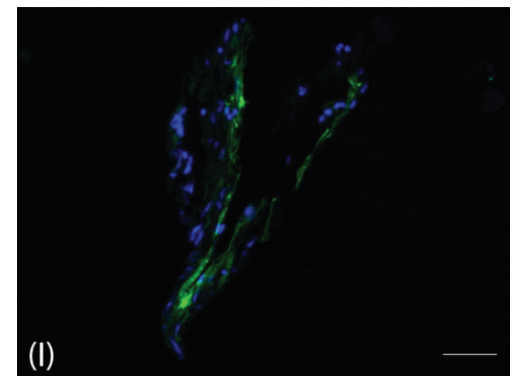

(i)

FIGURE 2: AQP1 expression in membranes from PVR and ERM. Images presented in each row represent different areas of the same membrane. (a-c) PVR number 1, (d-f) PVR number 2, and (e-g) ERM. AQP1 was immunolabelled in green, while cell nuclei were stained in blue with DAPI. Scale bars represent $50 \mu \mathrm{m}$.

to be specific for all the tested genes. Therefore, our results unambiguously authenticate the expression of AQP1, Acta2 (or $\alpha$ SMA), and GFAP mRNAs in both membranes from PVR and ERM.

\subsection{Immunofluorescent Detection of AQP1 Protein in Mem-} branes from PVR and ERM. The expression of AQP1, GFAP, and $\alpha$ SMA was next investigated by immunofluorescence on 10 membranes: 5 PVR and 5 ERM. No immunofluorescent staining was detected in the negative controls (Figure 3, first line). All membranes (both PVR and ERM) displayed AQP1 labelling. AQP1 expression was heterogeneous amongst and between the membranes from PVR and ERM (Figure 2). AQP1 immunoexpression was observed throughout the PVR and ERM membranes, with some variability related to the section of membranes studied. AQP1 was mostly expressed on the edges of the membranes (Figures 2 and 3 ).

In PVR and ERM membranes, the percentage of cells labelled for AQP1, $\alpha$ SMA, and GFAP was $23.89 \pm 5.43 \%$, $46.96 \pm 12.20 \%$, and $21.06 \pm 5.06 \%$, respectively, (Figure 4). In PVR and ERM membranes, the percentage of cells colabelled with AQP1/ $\alpha$ SMA was higher than the percentage of cells colabelled with AQP1/GFAP $(21.32 \pm 6.98 \%$ versus $8.20 \pm$ $3.61 \%, P=0.032$ ) (Figure 4).

In PVR and ERM, cells coexpressed AQP1/ $\alpha \mathrm{SMA}$ (Figures 3(d), 3(e), and 3(f)) or AQP1/GFAP (Figures 3(g), $3(\mathrm{~h})$, and $3(\mathrm{i})$ ). Interestingly, $\alpha \mathrm{SMA}$ and GFAP were expressed by distinct cell types, as no colocalisation could be found between these two markers (Figures 3(j), 3(k), and 3(l)). Image analysis at higher magnification allowed clearly to discriminate between cells expressing only one marker (empty arrow head), with respect to those coexpressing AQP1/ $\alpha \mathrm{SMA}$ (Figure $3\left(\mathrm{f}^{\prime}\right)$ ) or AQP1/GFAP (Figure 3( $\left.\mathrm{i}^{\prime}\right)$ ) (solid arrows) and those not coexpressing $\alpha \mathrm{SMA}$ and GFAP (Figure $3\left(\mathrm{l}^{\prime}\right)$ ) (empty arrow head).

Statistical analysis (using Spearman correlation test) highlighted that the percentages of cells labelled only by AQP1, GFAP, or $\alpha$ SMA were positively correlated to each other (Figure 5). The percentage of AQP1-labelled cells was significantly correlated to all the variables explored (Figure 5, first column). Indeed, the percentage of cells expressing AQP1 correlated significantly with that of cells expressing GFAP 


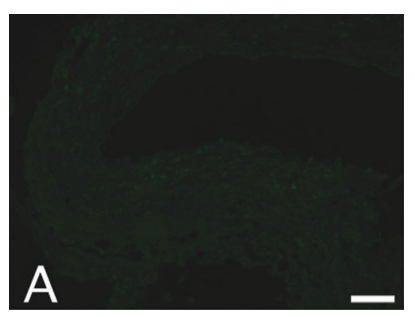

(a)

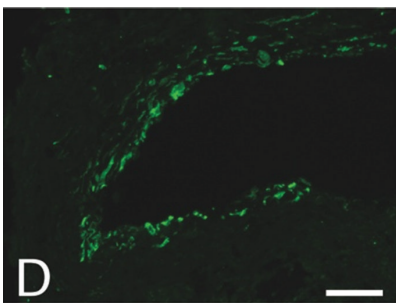

(d)

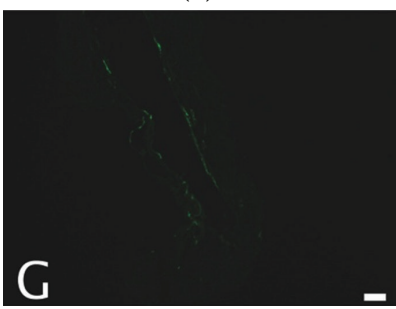

(g)

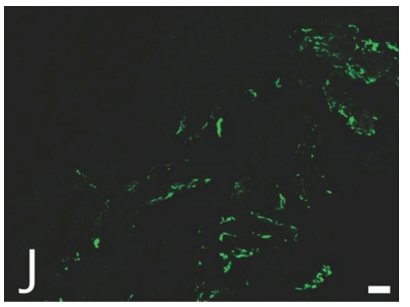

(j)

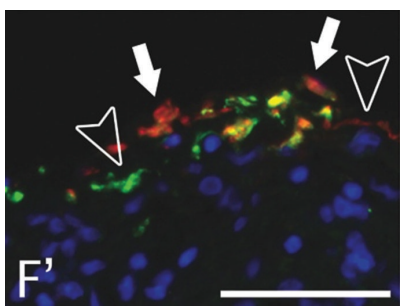

$\left(f^{\prime}\right)$

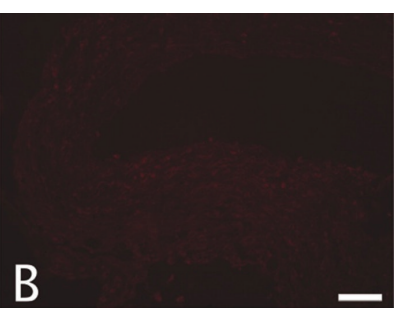

(b)

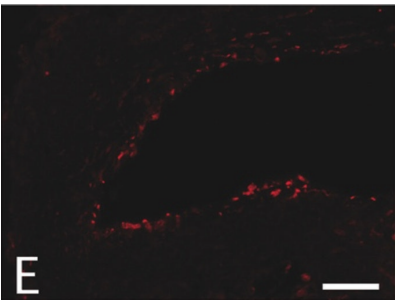

(e)

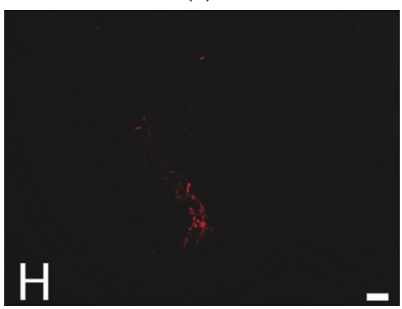

(h)

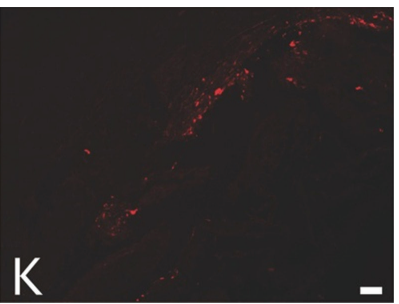

(k)

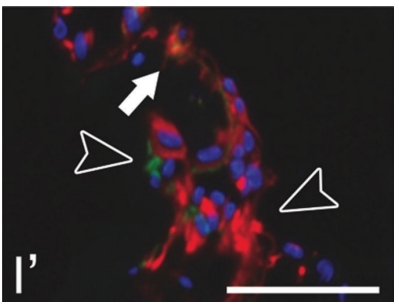

(i')

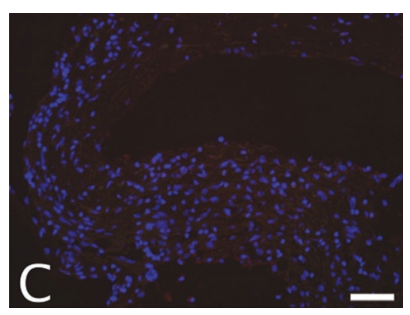

(c)

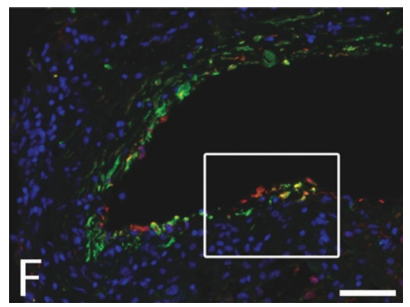

(f)

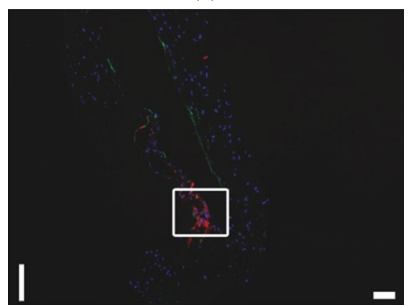

(i)

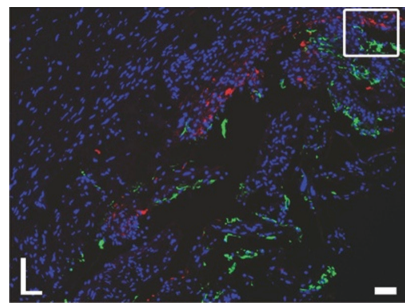

(l)

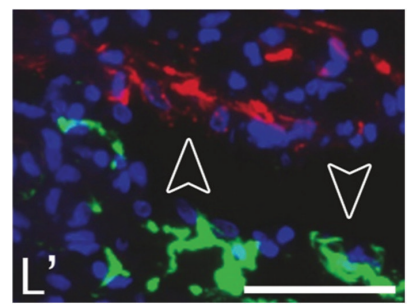

$\left(l^{\prime}\right)$

FIGURE 3: AQP1 expression colocalized with $\alpha$ SMA and GFAP. First row of images represents the negative control (a-c), respectively, in green, red, and blue (DAPI stains the cell nuclei). (d) AQP1 expression in green; (e) $\alpha \mathrm{SMA}$ expression in red; (f) AQP1 and $\alpha \mathrm{SMA}$ colocalisation (merge of (d) and (f) images) and DAPI; (g) AQP1 expression in green; (h) GFAP expression in red; (i) AQP1 and GFAP colocalisation (merge of ( $\mathrm{g}$ ) and (h) images) and DAPI; (j) GFAP expression in green; (k) $\alpha$ SMA expression in red; (l) lack of GFAP and $\alpha$ SMA colocalisation (merge of $(j)$ and $(k)$ images) and DAPI. $\left(f^{\prime}\right),\left(i^{\prime}\right)$, and $\left(l^{\prime}\right)$ represent a high magnification of the white square, respectively, drawn in the (f), (i), and (l) picture. Empty arrowheads designate single marker (AQP1 or $\alpha$ SMA or GFAP), while solid arrow point out coexpression of AQP1/ $\alpha$ SMA $\left(f^{\prime}\right)$ or AQP1/GFAP $\left(i^{\prime}\right)$. There was no colocalisation between GFAP and $\alpha$ SMA in the $\left(\mathrm{l}^{\prime}\right)$ picture. Empty arrowheads designate cells labelled by a single marker, either GFAP in green or $\alpha \mathrm{SMA}$ in red $\left(\mathrm{l}^{\prime}\right)$. Scale bars represent $50 \mu \mathrm{m}$.

$(\mathrm{CC}=0.685, P=0.029), \mathrm{AQP} 1 / \mathrm{GFAP}(\mathrm{CC}=0.903, P<$ $0.001), \alpha \mathrm{SMA}(\mathrm{CC}=0.867, P=0.001)$, and AQP1 $\alpha \mathrm{SMA}$ (0.988, $P<0.001)$ (Figure 5, first column). The percentage of cells expressing GFAP was positively correlated with cells coexpressing AQP1/GFAP $(\mathrm{CC}=0.576, P=0.082)$ but not significantly (Figure 5, second column). The percentage of cells expressing $\alpha \mathrm{SMA}$ correlated significantly with cells coexpressing AQP1/ $\alpha$ SMA $(\mathrm{CC}=0.879, P<0.001)$. 


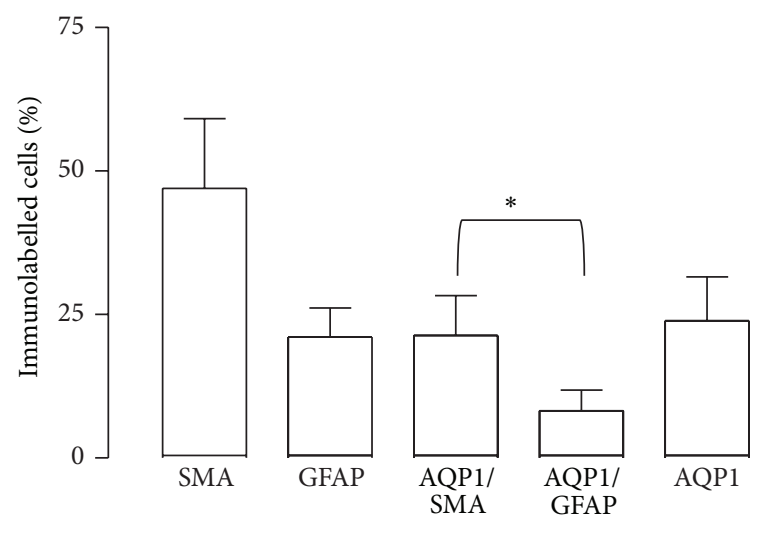

FIgURE 4: Quantification of cells expressing AQP1, $\alpha$ SMA, AQP1/ $\alpha$ SMA, GFAP, and AQP1/GFAP in PVR and ERM membranes (data are expressed as \% of total cell number (DAPI-labelled cells), mean \pm S.E.M.). Paired Student's $t$-test assessed the significant difference between the number of cells labelled with AQP $1 / \alpha \mathrm{SMA}$ and AQP1/GFAP $\left({ }^{*} P<0.05\right)$.

\section{Discussion}

In addition to its involvement in transcellular water transport, AQP1 water channel has recently been shown to be involved in cell migration and proliferation [20, 22-27, 36]. Membranes from ERM and PVR appear to be mainly formed as a result of RPE and glial cells that undergo proliferation and migrate onto the surfaces of the retina, although other cell types, such as inflammatory and immune cells, may contribute to the cell proliferation $[16,37]$. Prior to exploring if AQP1 could play a role in ERM and PVR development, we first needed to verify AQP1 expression at both the mRNA and protein levels.

In our study, we used membranes from both ERM and PVR. Although ERM and PVR are two different heterogeneous diseases, they share common characteristics such as proliferation, contractility, or cell population types [3741]. Due to recent changes in surgical technical procedures, we modified our routine vitrectomy from a 20-gauge to a 23-gauge surgery. The membranes peeled with 23-gauge instruments break easily and come in several small pieces making PVR and ERM membranes even more valuable as they contain very limited amounts of cells. Due to the common pathological characteristics and size limitations of the PVR and ERM samples, some PVR and ERM membranes were pooled in order to obtain reliable qPCR data.

The data herein demonstrate for the first time that both membranes from PVR and ERM express AQP1. Indeed, AQP1 mRNA was detected by RT-qPCR and AQP1 protein was detected by immunofluorescence. Furthermore, AQP1 protein expression was expressed heterogeneously amongst and between membranes from PVR and ERM (Figure 1). Heterogeneous expression of proteins is rather common, as recently illustrated for GFAP expression in epiretinal membranes from different pathological conditions [37]. Interestingly, preferential distribution of AQP1 was observed at the edge of PVR and ERM membranes and colocalized with either $\alpha$ SMA or GFAP. As cells at the edges of the membranes are usually recognized as being the cells involved in the proliferation and/or migration front, our latter observation may support the fact that AQP1 is indeed involved in cell proliferation and migration during ERM and PVR formation [25, 42, 43]. In accordance with a previous study performed on epiretinal membranes [44], there was no coexpression between $\alpha \mathrm{SMA}$ and GFAP. Therefore, AQP1 is likely to be expressed by at least two distinct cell types, likely myofibroblastes for AQP1/ $\alpha$ SMA colabelled cells and glial cells for AQP1/GFAP colabelled cells. Moreover, the percentage of cells labelled with $\mathrm{AQP} 1 / \alpha \mathrm{SMA}$ was significantly higher than that of cells labelled with AQP1/GFAP. Our data are in agreement with those showing higher number of cells labelled with $\alpha$ SMA than with GFAP in an experimental model of PVR [45].

During PVR, RPE undergo a dedifferentiation process and consequently lose their differentiation markers, such as RPE65 and ZO-1, and acquire dedifferentiation markers, such as $\alpha$ SMA and ZEB1 [46]. Therefore, we can speculate that the cells expressing AQP1/ $\alpha$ SMA are dedifferentiated RPE, while the cells expressing AQP1/GFAP are glial cells, possibly Müller cells or astrocytes.

Despite the controversial AQP1 expression by RPE cells $[33,35,47]$, the role of AQP1 in cell migration and proliferation has been well described [20, 22-27, 36, 48-50]. Therefore, it is tempting to hypothesise that AQP1 might indeed be involved in the development of both PVR and ERM, especially that preferential AQP1 expression was mostly observed at the edges of PVR and ERM samples. This hypothesis is supported by previous data showing the AQP1-dependent cell migration and AQP-facilitated water influx into dynamic cellular protrusions at the leading edge of endothelial cells [20]. Besides, the heterogeneous expression of AQP1 protein amongst and between PVR and ERM might be related to the proliferation status of the cells present in PVR and ERM. Nonetheless, statistical analysis broadly supports the impressions of the two independent investigators that suggest that the more the membranes express GFAP or $\alpha \mathrm{SMA}$, the more the membrane will express AQP1 and vice-versa. AQP1 expression could unfortunately not be correlated with clinical findings, as clinical grading is not easy and not well defined and not systematically done prior to surgery.

In conclusion, the data presented in this paper demonstrate for the first time the expression of AQP1, at both the mRNA and protein levels, in membranes from PVR and ERM. Cell types expressing AQP1 might be dedifferentiated RPE and glial cells as AQP1 positive cells expressed $\alpha$ SMA or GFAP. AQP1 is mostly expressed at the edges of PVR and ERM samples. These findings therefore suggest that AQP1 might indeed play a role in the cell migration and proliferation processes occurring during the development of PVR and ERM. These findings warrant further functional investigations aiming at elucidating the potential role of AQP1 in cell migration and proliferation occurring during the development of PVR and ERM.

\section{Conflict of Interests}

The authors declare that there is no conflict of interests regarding the publication of this paper. 

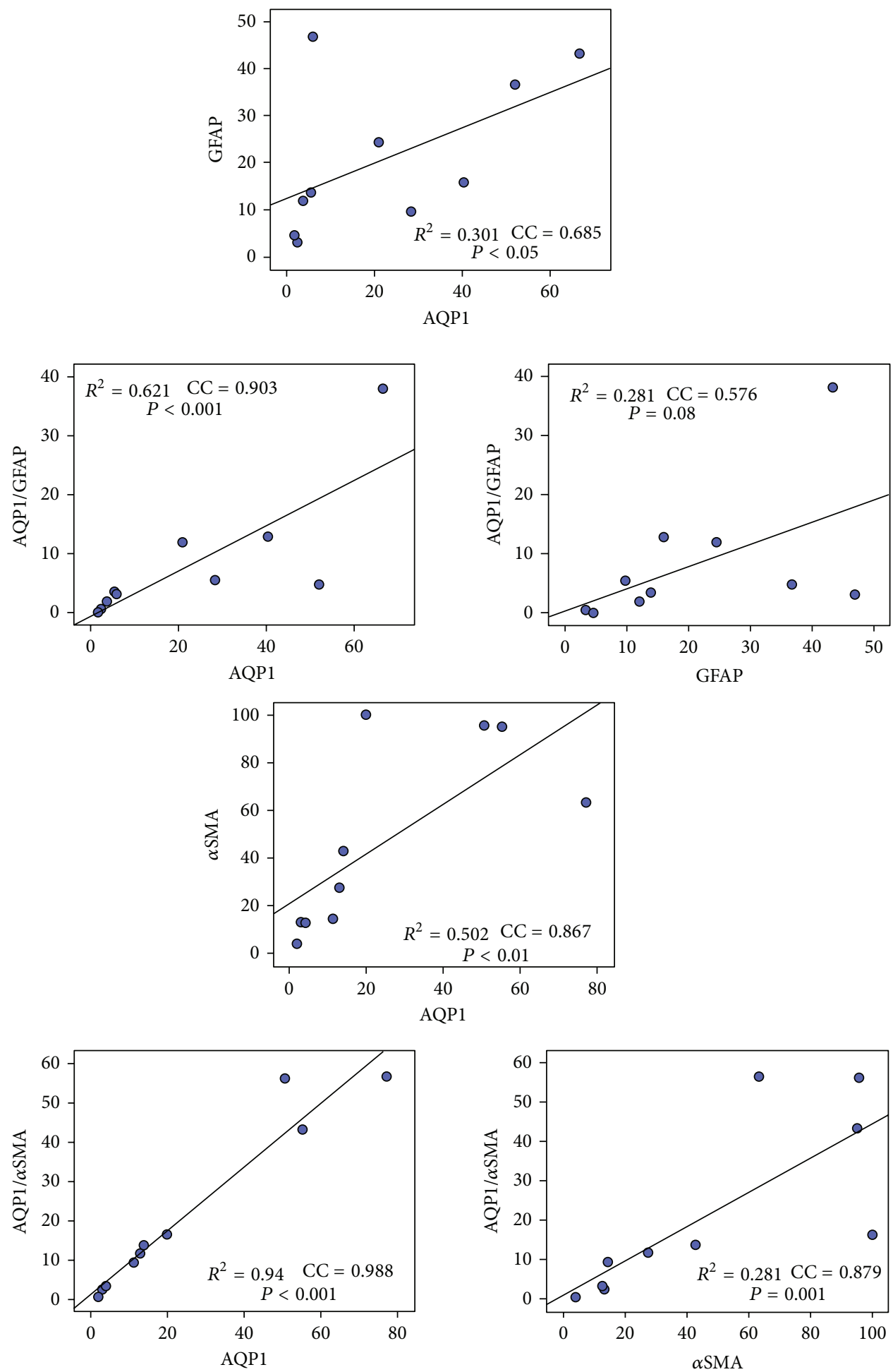

FIGURE 5: Correlation analysis of cells expressing AQP1, $\alpha$ SMA, and GFAP. All the cells labelled with DAPI, AQP1, $\alpha$ SMA, and GFAP, with two labels (AQP1/GFAP or AQP1/ $\alpha$ SMA), were counted and expressed as mean \pm S.E.M. $(n=10)$. All the combinations between the variables explored are shown in each graph, where dots represent the mean numbers of cells labelled in each membrane for the investigated variable. Straight lines on each graph represent the best fit linear regression and do not reflect Spearman rank correlation. $R^{2}$ indicates the coefficient of determination, CC is the Spearman correlation coefficient, and $P$ is the statistical level of significance. Spearman correlation tests were performed using IBM-SPSS statistical software. 


\section{Authors' Contribution}

François Willermain and Christine Delporte equally contributed to this paper.

\section{Acknowledgments}

This work was supported by Grants from the Fund for Medical Scientific Research (3.4502.09, Belgium) to Christine Delporte and from the Funds for Research in Ophthalmology (FRO, Belgium) and the association Vésale to Elie Motulsky. The authors would like to thank Professor V. De Maertelaer and Mr. P. Cullus from the Biostatistical and Medical Informatics Department of the Université Libre de Bruxelles for their statistical assistance.

\section{References}

[1] A. Mazure and I. Grierson, "In vitro studies of the contractility of cell types involved in proliferative vitreoretinopathy," Investigative Ophthalmology and Visual Science, vol. 33, no. 12, pp. 3407-3416, 1992.

[2] I. Grierson, A. Mazure, P. Hogg, P. Hiscott, C. Sheridan, and D. Wong, "Non-vascular vitreoretinopathy: the cells and the cellular basis of contraction," Eye, vol. 10, no. 6, pp. 671-684, 1996.

[3] R. Machemer, "Proliferative vitreoretinopathy (PVR): a personal account of its pathogenesis and treatment. Proctor lecture," Investigative Ophthalmology and Visual Science, vol. 29, no. 12 , pp. 1771-1783, 1988.

[4] C. M. Sheridan, N. L. Occleston, P. Hiscott, C. H. Kon, P. T. Khaw, and I. Grierson, "Matrix metalloproteinases: a role in the contraction of vitreo-retinal scar tissue," American Journal of Pathology, vol. 159, no. 4, pp. 1555-1566, 2001.

[5] D. McLeod, P. S. Hiscott, and I. Grierson, "Age-related cellular proliferation at the vitreoretinal juncture," Eye, vol. 1, no. 2, pp. 263-281, 1987.

[6] T. Kita, Y. Hata, R. Arita et al., "Role of TGF- $\beta$ in proliferative vitreoretinal diseases and ROCK as a therapeutic target," Proceedings of the National Academy of Sciences of the United States of America, vol. 105, no. 45, pp. 17504-17509, 2008.

[7] C. H. Ng, N. Cheung, J. J. Wang et al., "Prevalence and risk factors for epiretinal membranes in a multi-ethnic United States population," Ophthalmology, vol. 118, no. 4, pp. 694-699, 2011.

[8] S. Fraser-Bell, M. Guzowski, E. Rochtchina, J. J. Wang, and P. Mitchell, "Five-year cumulative incidence and progression of epiretinal membranes: the Blue Mountains eye study," Ophthalmology, vol. 110, no. 1, pp. 34-40, 2003.

[9] D. J. McCarty, B. N. Mukesh, V. Chikani et al., "Prevalence and associations of epiretinal membranes in the visual impairment project," American Journal of Ophthalmology, vol. 140, no. 2, pp. 288-el, 2005.

[10] A. P. Appiah and T. Hirose, "Secondary causes of premacular fibrosis," Ophthalmology, vol. 96, no. 3, pp. 389-392, 1989.

[11] S. N. Moysidis, A. Thanos, and D. G. Vavvas, "Mechanisms of inflammation in proliferative vitreoretinopathy: from bench to bedside," Mediators of Inflammation, vol. 2012, Article ID 815937, 2012.

[12] G. A. Peyman and J. Schulman, "Proliferative vitreoretinopathy and chemotherapeutic agents," Survey of Ophthalmology, vol. 29, no. 6, pp. 434-442, 1985.
[13] J. Sebag, "Shaken not stirred," Ophthalmology, vol. 108, no. 7, pp. 1177-1178, 2001.

[14] J. C. Pastor, E. R. De La Rúa, and F. Martín, "Proliferative vitreoretinopathy: risk factors and pathobiology," Progress in Retinal and Eye Research, vol. 21, no. 1, pp. 127-144, 2002.

[15] P. A. Hogg, I. Grierson, and P. Hiscott, "Direct comparison of the migration of three cell types involved in epiretinal membrane formation," Investigative Ophthalmology and Visual Science, vol. 43, no. 8, pp. 2749-2757, 2002.

[16] P. S. Hiscott, I. Grierson, and D. McLeod, "Natural history of fibrocellular epiretinal membranes: a quantitative, autoradiographic, and immunohistochemical study," British Journal of Ophthalmology, vol. 69, no. 11, pp. 810-823, 1985.

[17] A. Bringmann and P. Wiedemann, "Involvement of Müller glial cells in epiretinal membrane formation," Graefe's Archive for Clinical and Experimental Ophthalmology, vol. 247, no. 7, pp. 865-883, 2009.

[18] F. Zhao, A. Gandorfer, C. Haritoglou et al., "Epiretinal cell proliferation in macular pucker and vitreomacular traction syndrome: analysis of flat-mounted internal limiting membrane specimens," Retina, vol. 33, no. 1, pp. 77-88, 2013.

[19] P. Agre, "Aquaporin water channels," Bioscience Reports, vol. 24, no. 3, pp. 127-163, 2005.

[20] S. Saadoun, M. C. Papadopoulos, M. Hara-Chikuma, and A. S. Verkman, "Impairment of angiogenesis and cell migration by targeted aquaporin-1 gene disruption," Nature, vol. 434, no. 7034, pp. 786-792, 2005.

[21] M. Hara-Chikuma and A. S. Verkman, "Aquaporin-3 facilitates epidermal cell migration and proliferation during wound healing," Journal of Molecular Medicine, vol. 86, no. 2, pp. 221-231, 2008.

[22] M. Hara-Chikuma and A. S. Verkman, "Aquaporin-1 facilitates epithelial cell migration in kidney proximal tubule," Journal of the American Society of Nephrology, vol. 17, no. 1, pp. 39-45, 2006.

[23] E. McCoy and H. Sontheimer, "Expression and function of water channels (aquaporins) in migrating malignant astrocytes," Glia, vol. 55, no. 10, pp. 1034-1043, 2007.

[24] J. Ruiz-Ederra and A. S. Verkman, "Aquaporin-1-facilitated keratocyte migration in cell culture and in vivo corneal wound healing models," Experimental Eye Research, vol. 89, no. 2, pp. 159-165, 2009.

[25] S. Hayashi, N. Takahashi, N. Kurata et al., "Involvement of aquaporin-1 in gastric epithelial cell migration during wound repair," Biochemical and Biophysical Research Communications, vol. 386, no. 3, pp. 483-487, 2009.

[26] E. Monzani, R. Bazzotti, C. Perego, and C. A. M. La Porta, "AQP1 is not only a water channel: It contributes to cell migration through Lin7/beta-catenin," PLoS ONE, vol. 4, no. 7, Article ID e6167, 2009.

[27] F. Meng, Y. F. Rui, L. Xu, C. Wan, and G. Li, "Aqp1 enhances migration of bone marrow mesenchymal stem cells through regulation of FAK and beta-catenin," Stem Cells and Development, vol. 23, no. 1, pp. 66-75, 2013.

[28] S. Vogler, T. Pannicke, M. Hollborn et al., "Muller cell reactivity in response to photoreceptor degeneration in rats with defective polycystin-2," PLoS ONE, vol. 8, no. 6, Article ID e61631, 2013.

[29] M. Fukuda, Y. Nakanishi, M. Fuse et al., "Altered expression of aquaporins 1 and 4 coincides with neurodegenerative events in retinas of spontaneously diabetic Torii rats," Experimental Eye Research, vol. 90, no. 1, pp. 17-25, 2010. 
[30] W. Xun, Y. Liu, G. Qing, X. Xun, Z. Dongqing, and W. Haixiang, "Aquaporin 1 expression in retinal neovascularization in a mouse model of retinopathy of prematurity," Preparative Biochemistry and Biotechnology, vol. 39, no. 2, pp. 208-217, 2009.

[31] I.-B. Kim, S.-J. Oh, S. Nielsen, and M.-H. Chun, "Immunocytochemical localization of Aquaporin 1 in the rat retina," Neuroscience Letters, vol. 244, no. 1, pp. 52-54, 1998.

[32] I. Iandiev, T. Pannicke, M. B. Reichel, P. Wiedemann, A. Reichenbach, and A. Bringmann, "Expression of aquaporin-1 immunoreactivity by photoreceptor cells in the mouse retina," Neuroscience Letters, vol. 388, no. 2, pp. 96-99, 2005.

[33] W. D. Stamer, D. Bok, J. Hu, G. J. Jaffe, and B. S. McKay, "Aquaporin-1 channels in human retinal pigment epithelium: role in transepithelial water movement," Investigative Ophthalmology and Visual Science, vol. 44, no. 6, pp. 2803-2808, 2003.

[34] T. Arsenijevic, F. Gregoire, V. Delforge, C. Delporte, and J. Perret, "Murine 3T3-L1 adipocyte cell differentiation model: validated reference genes for qPCR gene expression analysis," PLoS ONE, vol. 7, no. 5, 2012.

[35] E. Motulsky, P. Koch, S. Janssens et al., "Aquaporin expression in blood-retinal barrier cells during experimental autoimmune uveitis," Molecular Vision, vol. 16, pp. 602-610, 2010.

[36] B. Nico and D. Ribatti, "Role of aquaporins in cell migration and edema formation in human brain tumors," Experimental Cell Research, vol. 317, no. 17, pp. 2391-2396, 2011.

[37] S. Y. L. Oberstein, J. Byun, D. Herrera, E. A. Chapin, S. K. Fisher, and G. P. Lewis, "Cell proliferation in human epiretinal membranes: characterization of cell types and correlation with disease condition and duration," Molecular Vision, vol. 17, pp. 1794-1805, 2011.

[38] A. M. Abu El-Asrar, L. Missotten, and K. Geboes, "Expression of myofibroblast activation molecules in proliferative vitreoretinopathy epiretinal membranes," Acta Ophthalmologica, vol. 89, no. 2, pp. el15-e121, 2011.

[39] A. M. Abu El-Asrar, L. Missotten, and K. Geboes, "Expression of autotaxin and acylglycerol kinase in proliferative vitreoretinal epiretinal membranes," Acta Ophthalmologica, vol. 90, no. 2, pp. e84-e89, 2012.

[40] A. M. Abu El-Asrar, P. E. Van den Steen, S. A. Al-Amro, L. Missotten, G. Opdenakker, and K. Geboes, "Expression of angiogenic and fibrogenic factors in proliferative vitreoretinal disorders," International Ophthalmology, vol. 27, no. 1, pp. 11-22, 2007.

[41] R. Walshe, P. Esser, P. Wiedemann, and K. Heimann, "Proliferative retinal diseases: myofibroblasts cause chronic vitreoretinal traction," British Journal of Ophthalmology, vol. 76, no. 9, pp. 550-552, 1992.

[42] S. Etienne-Manneville, "Microtubules in cell migration," Annual Review of Cell and Developmental Biology, vol. 29, pp. 471499, 2013.

[43] M. J. Simpson, K. K. Treloar, B. J. Binder et al., "Quantifying the roles of cell motility and cell proliferation in a circular barrier assay," Journal of the Royal Society, Interface, vol. 10, no. 82, 2013.

[44] R.-I. Kohno, Y. Hata, S. Kawahara et al., "Possible contribution of hyalocytes to idiopathic epiretinal membrane formation and its contraction," British Journal of Ophthalmology, vol. 93, no. 8, pp. 1020-1026, 2009.

[45] H. Basmak, S. Isiksoy, S. Topbas, S. Artan, and S. Yurdakul, "Experimental tractional retinal detachment: an immunohistochemical study," European Journal of Ophthalmology, vol. 8, no. 2, pp. 112-117, 1998.
[46] H. Li, H. Wang, F. Wang, Q. Gu, and X. Xu, "Snail involves in the transforming growth factor $\beta 1$-mediated epithelialmesenchymal transition of retinal pigment epithelial cells," PLoS ONE, vol. 6, no. 8, Article ID e23322, 2011.

[47] M. H. Levin and A. S. Verkman, "Aquaporins and CFTR in ocular epithelial fluid transport," Journal of Membrane Biology, vol. 210, no. 2, pp. 105-115, 2006.

[48] A. S. Verkman, M. Hara-Chikuma, and M. C. Papadopoulos, "Aquaporins-new players in cancer biology," Journal of Molecular Medicine, vol. 86, no. 5, pp. 523-529, 2008.

[49] S. C.-H. Kao, N. Armstrong, B. Condon et al., "Aquaporin 1 is an independent prognostic factor in pleural malignant mesothelioma," Cancer, vol. 118, no. 11, pp. 2952-2961, 2012.

[50] M. Endo, R. K. Jain, B. Witwer, and D. Brown, "Water channel (aquaporin 1) expression and distribution in mammary carcinomas and glioblastomas," Microvascular Research, vol. 58, no. 2, pp. 89-98, 1999. 


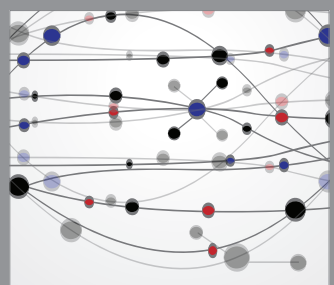

The Scientific World Journal
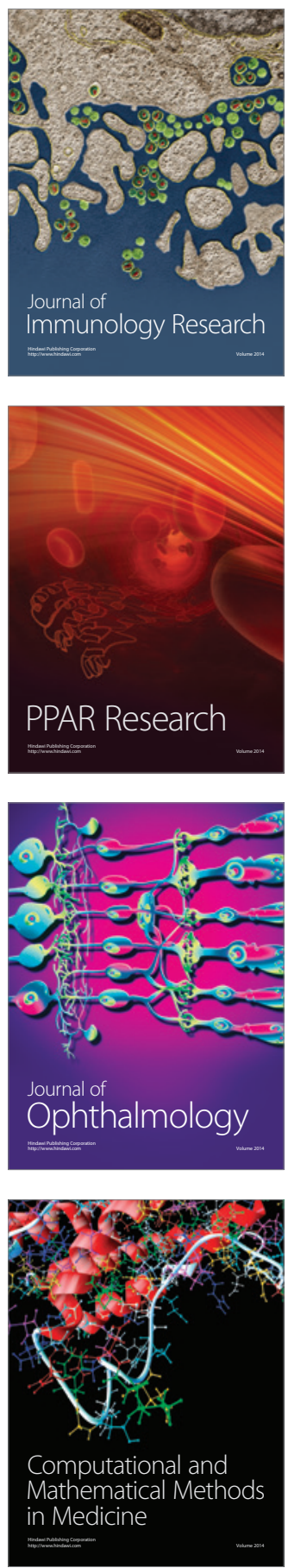

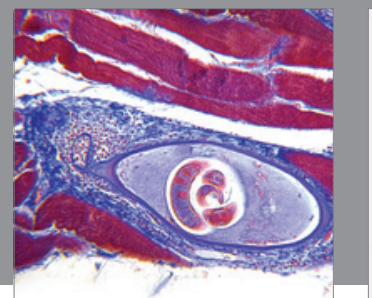

Gastroenterology

Research and Practice
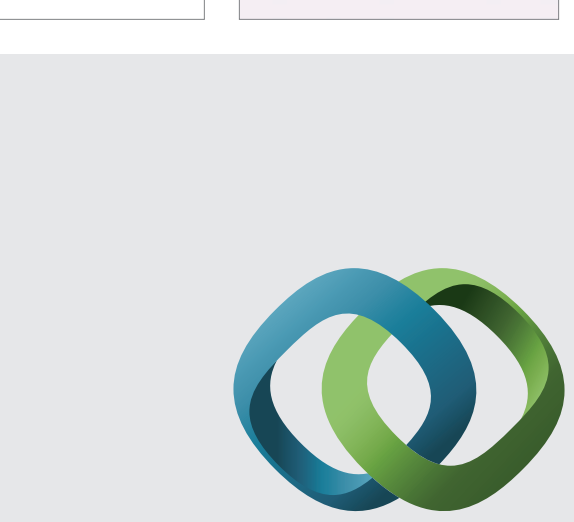

\section{Hindawi}

Submit your manuscripts at

http://www.hindawi.com
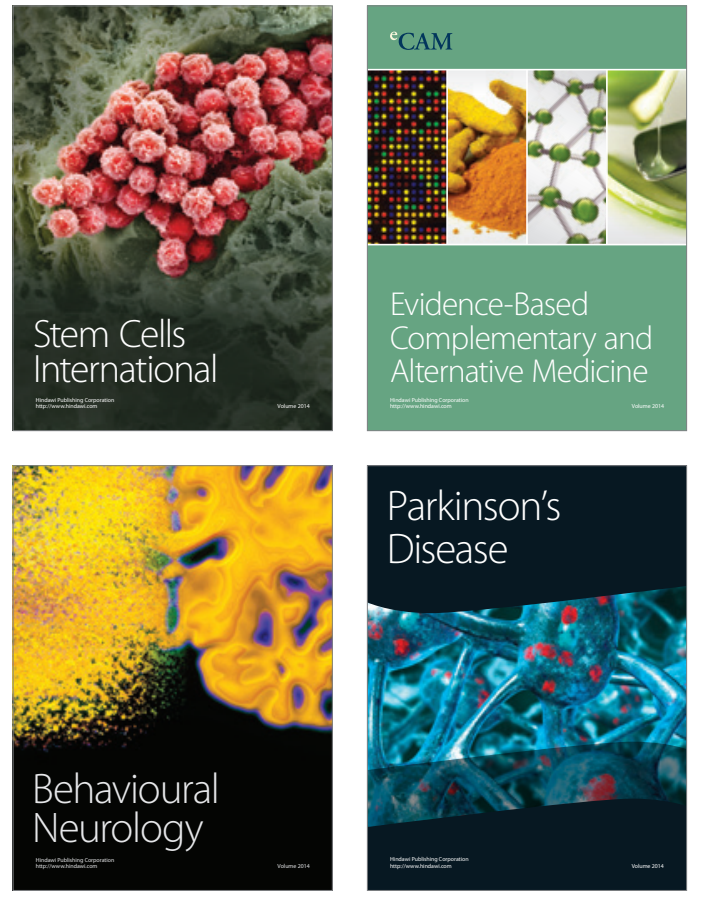
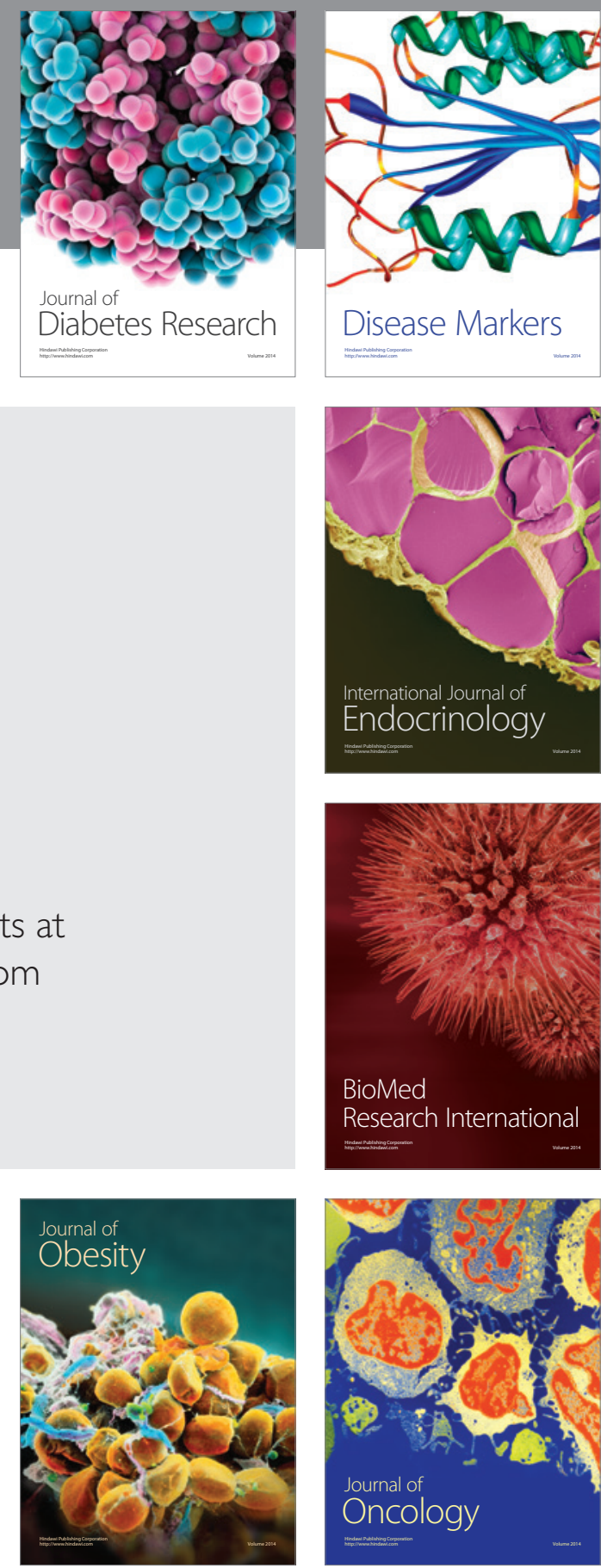

Disease Markers
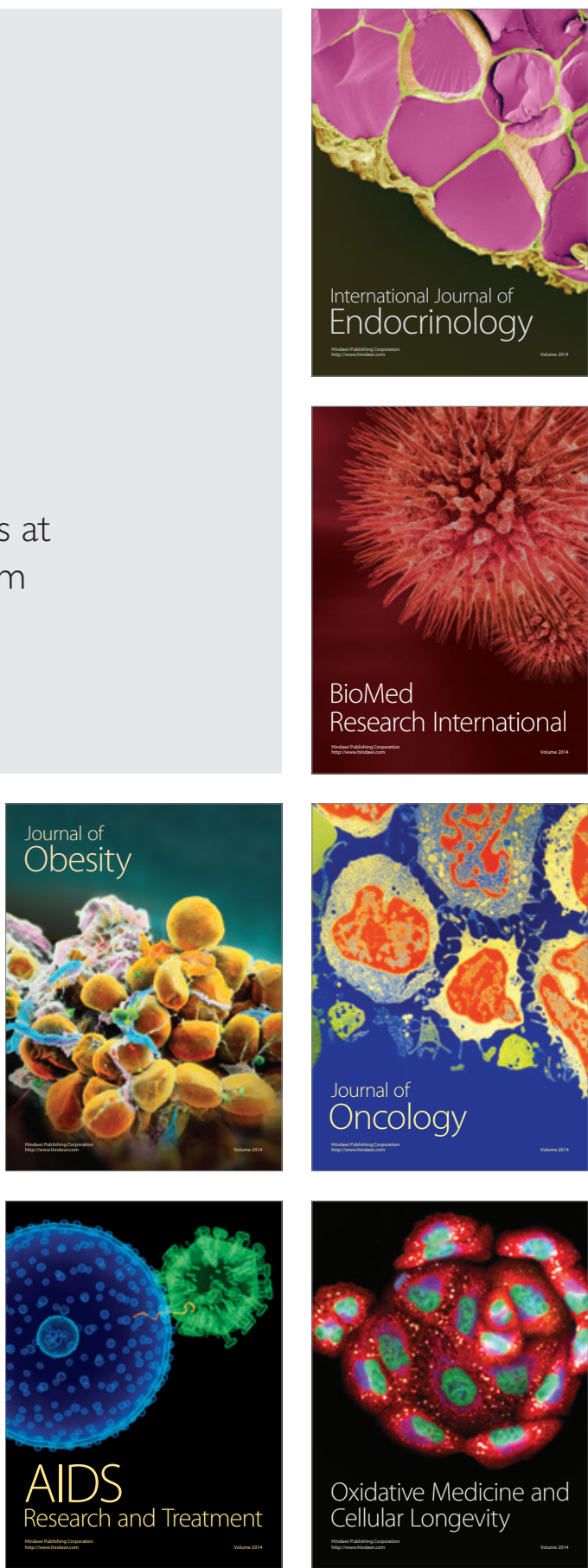